\title{
GLASS: RECENT RESEARCH AND DEVELOPMENTS
}

$\mathrm{T}$ HE systematic study of glass and the subject of glass technology is a field with which the University of Sheffield is particularly associated, Sheffield being the only University in the United Kingdom which has a Department of Glass Technology, and, in fact, this was the first such Department in the world.

The existence of this Department and its growth is largely due to the work and vision of Prof. W. E. S. Turner, who first organized the Department in 1915 and became the first professor of glass technology in 1920. It was very fitting, therefore, that Prof. Turner should have been present to give an introductory talk to the meeting of Section B (Chemistry) of the British Association on September 4 at Sheffield which was devoted to glass. In his talk, Prof. Turner dealt with the history and development of the subject since 1910, the year in which the British Association last met in Sheffield. He referred to the parts which chemistry, physics and engineering have played, and continue to play, in the extension of understanding and practice in the industry, themes which were developed by the subsequent speakers.

Prof. R. W. Douglas, the present occupant of the chair of glass technology in the University of Sheffield, spoke on the nature of glass. After stressing the importance of the viscosity of glass and the manner in which it varies with temperature in glass manufacturing processes, he said that this relation of viscosity with temperature is of fundamental im. portance in any discussion of the chemistry and physics of glass. The high viscosity is associated with the nature of the forces between the atoms; the directed bonds between silicon and oxygen being particularly important.

Silica melts at $1,713^{\circ} \mathrm{C}$; ; but the liquid so formed flows with great difficulty because of these strong directed forces, and it is easy to cool the liquid through its freezing point without its solidifying. It is this mechanism which makes the formation of glass possible, and in this sense glasses are supercooled liquids.

On cooling further, a second stage of thermodynamic instability is reached. The distribution function of a liquid has a particular value for each temperature; but the difficulty of the atoms moving in respect to one another increases rapidly as the temperature falls, until the time taken for the distribution function to reach the value appropriate to the lower temperature becomes long compared with the time taken to make an experimental measurement. The properties of glass then appear to vary with time towards equilibrium values corresponding to the temperature of the experiment. This behaviour is observed when the temperature falls below that at which glass has a viscosity of about $10^{13}$ poises.

Eventually, after cooling roughly another hundred degrees, the rate of approach to equilibrium configuration becomes so slow that the distribution function is fixed. At room temperature glass is therefore a very special type of solid which has the macroscopic mechanical properties of a solid but in which the atoms are arranged with the disorder of those of a liquid and in which thermal motion of translation has ceased.
The function of other oxides, added to silica to produce glasses which have properties required for ease of fabrication, were mentioned briefly.

This theme was taken up by Mr. W. J. R. Merren, of Pilkington Brothers, Ltd., who dealt with new glasses. This title included many special kinds of glass which had been prepared to meet the demands of scientific development, the needs of research, and of new developments in various industries.

New optical glasses which have very high refractive indices were mentioned; these contain considerable amounts of the rare-earth element, lanthanum. Another development in optical glasses has been the production of glass of extremely high transparency. This involves the use of very pure materials and the melting of the glass batch in platinum vessels on a commercial scale.

Other glasses have been developed which absorb infra-red radiation, and are very useful, for example, in projectors to prevent overheating of the slides. Glasses are also required which transmit infra-red radiation. In preparing these glasses it is important to reduce, so far as possible, the very small amount of water which ordinary glasses can contain, for this small amount is enough to cause very marked absorption. It seems that for work beyond $5 \mu$, glasses based on silica will not be useful; in this region selenium and sulphide glasses can be used, arsenic sulphide glass transmitting out to $15 \mu$.

The developments in atomic energy have also made demands on the glass technologist. Radiationabsorbing glasses have been sought for one type of protective window, and a lead glass which contains as much as 80 per cent lead oxide has been made for this window. A window $3 \mathrm{ft} . \times 2 \mathrm{ft} . \times 2 \mathrm{ft}$. (the great thickness is necessary to get sufficient absorbing power) will weigh about $4,000 \mathrm{lb}$. A similar glass, when especially pure and transparent, has found application as a $\gamma$-ray detector by using the Cerenkov radiation.

Certain glasses have the property of changing under the action of harmful radiation, either developing a colour or an ability to fiuoresce which they did not possess before, and so can be used to measure the 'dose' of radiation to which they have been exposed. Glasses such as these are quite different from the normal soda-lime-silica glass. Glasses for absorbing $\mathrm{X}$-rays, for example, may contain large quantities of elements such as tantalum, boron, phosphorus and germanium, while the dosimeter glasses are potassium, barium, aluminium phosphates with as much as 7 per cent silver in them.

Dr. J. H. Partridge, of the General Electric Co., Ltd., continued Mr. Merren's theme, dealing with the demands which the lamp and electronic industry has made for new glasses. Here again, constituents which had not been thought of as useful in glassmaking thirty years ago are being used, or constituents. such as soda and other alkaline oxides which were considered essential in earlier times are omitted. For example, the inner tube of the mercury lamp which is familiar in street lighting installations is made of a glass which contains no alkali. At $700^{\circ} \mathrm{C}$. an evacuated tube of this glass about $30 \mathrm{~mm}$. in diameter and $1 \mathrm{~mm}$. wall thickness will become distorted only very slowly. 
Another glass, used for making the sodium discharge lamp, is remarkable in that it contains no silica. This is in order that it shall withstand the attack of the sodium vapour. Other special glasses have had to be developed in order that suitable wires can be sealed through glass to secure and make contact with the electrodes in thermionic devices; such glasses must have a very high electric resistance. Dr. Partridge's paper was illustrated by an excellent colour film of glass-making operations; this film emphasized the changes in normal procedure entailed in making articles from some of these special glasses.

A paper different from the others, in that it dealt with a new industry which has grown out of the glass industry itself, was presented by Dr. A. De Dani, of Fibre Glass, Ltd. Glass fibres may be drawn as single continuous fibres or by the glass wool process. This process consists in subjecting a stream of glass issuing from a platinum orifice to an intense blast of superheated steam. The stream of glass is thus shattered, resulting in a multitude of very fine fibres of glass. It was thought at one time that the steam shattered the glass into droplets which were then drawn into fibres, but calculations showed that this explanation was not very probable. The process has therefore been investigated using high-speed ciné photography.

Some of the films taken in the experiments were shown to the meeting. The audience was thus able to see an example of industrial research in a new development of the glass industry, thereby completing the review of the many-sided aspects of glass technology-a subject in which physics and chemistry must be applied for a fundamental understanding of the material, in which physics, chemistry, engineering and mathematics are applied in the industrial development, and an industry which, although several thousand years old, is now, with few exceptions, such as high-quality table-ware and decorative pieces and the production in small quantities of special glasses, a fully mechanized industry.

\section{SEVENTH INTERNATIONAL ASTRONAUTICAL CONGRESS}

$\mathrm{T}$ HE Seventh International Astronautical Congress was held in Rome this year during September 17-22, and was attended by more than four hundred delegates from many various countries and of equally varied interests. There is, of course, practically no scientific subject which is not involved in astronautics one way or another, and which does not stand to profit from its findings. The proceedings took place in the magnificent Congress Hall of the Espozisione Universale di Roma, and during the two and a half days of technical sessions more than forty papers were presented. An unusual feature-at least for a scientific meeting-was the use of a simultaneous translation service in Italian, French, German and English. Despite the valiant efforts of the Italian linguists providing this service, it would no doubt have been improved had the translators been natives of the country into whose language they translated, and had they had a knowledge of scientific terminology. These stern requirements would seem-necessary to ensure the complete success of such a service.

With so many papers to be presented, only a quarter of an hour was allotted to each speaker, and there was practically no time for formal discussion. This made the task of digesting the contents of many of the lectures difficult, particularly as many of them were not available in printed form. Special interest was aroused by the contributions of the delegation from the United States, who, numbering among them the first professional 'astronautical engineers', introduced an atmosphere of reality unusual in conferences on this subject. With regard to the speculations concerning the relative progress of the American and Soviet attempts to set up an artificial Farth satellite, it is not inappropriate to remark that the only Soviet delegate, Prof. I. I. Sedov, of the U.S.S.R. Academy of Sciences, disclaimed any knowledge of his countrymen's progress in this venture and declined to make any statement on the subject.

The American artificial satellite, or to give it its code name, 'Project Vanguard', formed the subject of many papers. It is to be a three-stage rocket, appearing, however, to be composed of only two stages, because the last stage is carried inside the second. The initial stage is $44 \mathrm{ft}$. long and 45 in. in diameter, and is powered by a liquid oxygen rocket with kerosene as a fuel, and pressurized by helium; it is intended to carry the projectile to a height of 36 miles, and to achieve an all-burnt velocity of $5,500 \mathrm{ft}$. $/ \mathrm{sec}$. The casing of the initial stage, after being jettisoned, is expected to land at a distance of 75 miles from the launching station. The second stage is $32 \mathrm{ft}$. long, and employs a bifuel rocket unit with nitric acid and hydrazine hydrate as propellants, and also pressurized by helium. It is expected to increase its speed to $13,400 \mathrm{ft}$./sec. at all-burnt, when its height would be 140 miles. Besides enclosing the final stage, it contains the control and guidance equipment, which is to be brought into action during a period of coasting flight after the operation of the second-stage rocket, to effect the critical final adjustments to the course of the projectile. The final stage of the rocket is then spin-stabilized, and launched from within the nose of the second. It consists of a solid-fuel rocket mounted on a magnesium alloy sphere, 20 in. in diameter, which is the Earth satellite itself. The final velocity would have to be about $26,000 \mathrm{ft}$. $/ \mathrm{sec}$. and it is anticipated that the perigee of the satellite's orbit would be about three hundred miles from the surface of the Earth. When the casing of the solid rocket is at last jettisoned, about ten minutes will have elapsed since take-off, and the satellite will have travelled some fifteen hundred miles from the launching point.

The projectile is finless, and control on the first two stages is to be obtained by deflecting the rocket venturi on gimbals. A considerable degree of accuracy in both final speed and direction of motion is required if the orbit is to be successfully established. As an example, if there is no error in speed and if the perigee is not to be less than two hundred miles above the Earth, nor the apogee more distant than eight hundred miles, an angular error of about $3^{\circ}$ in 